\title{
PUBLIC ENTERPRISE INVESTMENT AND ECONOMIC STABILITY: A SIX COUNTRY COMPARISON*
}

\author{
by \\ Wayne W. SNYDER, \\ Center for Research on Economic Development, \\ University of Michigan (Ann Arbor, Michigan, U.S.A.)
}

In the considerable volume of economic literature on public enterprise, one area appears to have been largely overlooked: the impact of public enterprise investment on economic stability. This omission is somewhat surprising, because for several decades economists have demonstrated a growing interest in the relationship of other governmental expenditures and revenues to economic stability. Most of that literature is concerned with the effect of central government budget changes, although in some countries the relationship of state and local government budgets to economic stability has also been studied, and, of course, the automatic or built-in stabilizing effects of social security systems have long been recognized.

The lack of study of the stabilizing effects of public enterprise investment may be due in part to the belief that investment is primarily determined by reasons that have little to do with conjunctural considerations, and that anyway its determination is largely outside the influence of the central government. Both positions are open to question, and in any case public enterprise investment does have a de facto impact, the importance of which is worth studying regardless of whether the government uses or is capable of using it as one means of attempting to achieve economic stability.

Our purpose in this paper is to determine the extent to which public enterprise investment was a stabilizing or destabilizing factor during the eleven-year period from 1955 through 1965 for six countries: Belgium, France, Italy, Sweden, the United Kingdom, and the United States. ${ }^{1}$ The methods of estimating the impact of that investment are

* I am particularly indebted to J.C.R. Dow, who conceived and directed the OECD study of fiscal policy [4], and to Bent Hansen, with whom I had the pleasure of working for two years on completing it. I also benefitted from the helpful editorial assistance of Janet Eckstein.

1 A seventh country, Germany, was included in the Hansen study, but no complete data are available concerning its public enterprise investments. 
the same as those developed for a recent OECD survey by Bent Hansen [3], which gives the institutional background for budgetary action and analyzes the nature and effects of fiscal policy for seven OECD member countries between 1955 and 1965 . This paper supplements the Hansen study by singling out public enterprise investment.

\section{Measuring the Effects of Public Enterprise Investment}

The model developed by Hansen to measure the effects of various types of budget changes draws on the previous contribution of Brown [1], Hansen [4], Lindbeck [5], and Musgrave [6]. Although Hansen's model is admittedly simple compared with the large econometric models which have been developed for some countries (partly because he wanted to use a common analysis for each country), it is adequate to measure the relative importance of various kinds of budget changes both within and among countries. Because there were no quarterly data for some countries, his model uses year-to-year changes, and no lags are introduced. The model assumes that private investment, exports, and prices are exogenously determined. Imports are endogenous and for some countries (e.g., Belgium and Sweden) represent the principal leakage of potential budget effects. ${ }^{2}$

The combination of the direct and the multiplier effects, or the total effects, of budget changes are estimated by the following equation:

$$
\text { Total effects }=\frac{1}{1-\alpha(1-\mu)}\left[d I+\alpha(1-\mu)\left(\operatorname{Idp}_{I}\right)\right]
$$

where $\alpha$ is the marginal propensity to consume, $\mu$ is the marginal propensity to import, $\mathrm{dI}$ is the annual change in the volume of public enterprise investment, and $I d p_{I}$ is the annual change in the value of public enterprise investment due to price changes. The leakage coefficients $\alpha$ and $\mu$ vary, of course, among countries, and consequently the multipliers for the effects due to changes in the volume and price of public enterprise investment differ also. These multipliers allow only for leakages via private savings and imports, and exclude leakages via tax changes and spending induced by the changes in public enterprise investment itself. The effects of tax changes are excluded, because they are included in the impact of general or central government, which is discussed later. If leakages due to tax changes were explicitly included, the effects of public enterprise investment would be diminished for each country but its relative position among the countries would not be affected.

2 For a complete description of the methods used to measure budgetary effects, see Hansen [4], Chapter 1. 
The year-to-year variations in the total effects of changes in public enterprise investment, expressed as a percentage of GNP, are given in Table 1. Before we evaluate whether these have been generally stabilizing or not, several comments may be helpful. Several factors account for differences in the typical impact, whether expansionary or dampening, among countries: the relative size of the public enterprise sector and its annual investment, and the relative importance of those two multipliers. For example, France, Sweden, and the United Kingdom all have large public enterprise sectors whose investment normally exceeds 5 per cent of GNP, but the typical impact was nearly 2 per cent of GNP in France and only about 0.5 per cent in Sweden and the United Kingdom. The difference is due partly to the more rapid expansion of the public enterprise sector in France, but it is also due to the smaller multiplier effects in Sweden and the United Kingdom, where import leakages substantially reduce the potential effects of public enterprise investment. The public enterprise sector expanded most rapidly in Italy, where its investment increased from 2 per cent of GNP in 1955 to 4 per cent in 1965. As the sector was relatively small in 1955, the average impact was not as large as in France, but it did amount to about 1 per cent of GNP annually, the second highest among the countries studied. In Belgium the public enterprise sector was smaller than in the countries already mentioned and did not change much during the period covered. In fact, the average impact amounted to only about 0.1 per cent of GNP. The same was true in the United States, where the public enterprise sector was by far the smallest among the countries studied, and where investment amounted to less than 0.5 per cent of GNP. Year-to-year changes were often important, especially when the large multiplier effects are included, so that a typical impact amounted to about 0.5 per cent of GNP, although the numerous times when the effect was dampening more than compensated for the expansionary effects which resulted in the average effect having a slight dampening impact.

\section{Evaluating the Impact of Public Enterprise Investment}

No single criterion is clearly the only one by which the impact of public enterprise investment on economic stability can be judged. Three of the possible criteria are discussed in this paper. The first evaluation attempts to judge the short-run stabilizing effects by simply determining whether the actual growth rate of GNP would have been more or less stable without the impact of public enterprise investment. Figure 1 illustrates the relevant relationships which are necessary in order to make this assessment: the average GNP-growth rate, the actual rate, and a measure of how GNP might have developed in the absence of the impact of any public enterprise investment (but including the budgetary effects of the order government sector-central and state and 


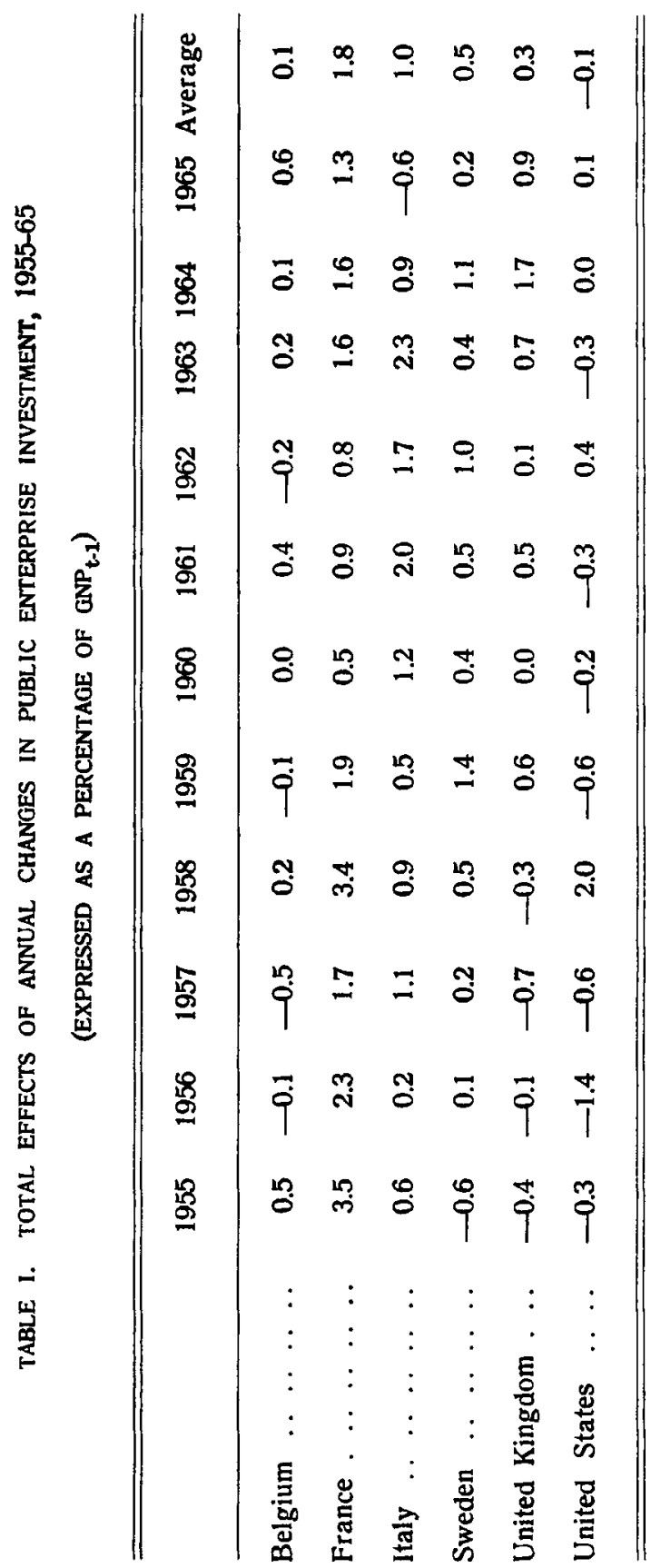


local government and the social security system-as well as the combined influence of all other exogenous and endogenous factors). The latter measure is obtained by subtracting the total effects of public enterprise investment from the actual GNP growth rate (see Table 2). For example, in Belgium during 1955 the total effects amounted to +0.5 per cent of GNP and, ceteris paribus, contributed to pushing the actual growth rate that much higher above the average rate than it otherwise would have been-by definition a case where the budget impact was destabilizing.

The net stabilizing (or destabilizing) effect over a number of years is simply the accumulated sum of the (gross) stabilizing minus the destabilizing effects; these and other relevant data are given in Table 2. The net effects were stabilizing in only two countries, France and the United States, and on balance they had a destabilizing impact in the remaining four countries, Belgium, Italy, Sweden, and the United Kingdom. It must be immediately noted, however, that on average the net effects were generally quite small, amounting to no more than 0.1 per cent of GNP annually except in France, where they were more than 1 per cent, and the United Kingdom, where they were about 0.3 per cent.

TABLE 11. THE ACCUMULATED STABILIZING EFFECTS

OF PUBLIC ENTERPRISE INVESTMENT, 1955-65

Belgium France Italy Sweden $\begin{gathered}\text { United United } \\ \text { Kingdom States }\end{gathered}$

1. Net stabilizing effects of expressed as \% of GNP $\mathrm{t}_{\mathrm{t}-1}$ public enterprise investment

$\begin{array}{lllllllll}\text { a. Gross stabilizing } & \ldots & \ldots & 1.0 & 16.0 & 5.6 & 2.4 & 1.4 & 3.2\end{array}$

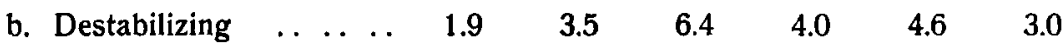

2. Net stabilizing effect in relation to "pure cycle" .

$0.1 \quad 6.7$

a. Gross stabilizing ....

$1.5 \quad 13$.

b. Destabilizing

1.4

$6.7-2.6$

$\begin{array}{ll}1.2 & -3.2\end{array}$

0.6

3. Potential stabilization for "pure cycle" . . . . . . 24.3

4. Percentage of potential stabilization achieved . .... 24

a. General government ... 24

b. Public enterprise investment .......... $24 \quad 45$ expressed as \%

$\begin{array}{llllll}24 & 13 & 42 & 35 & 5\end{array}$

$\begin{array}{lllllll}0 & 32 & -13 & 5 & -28 & 1\end{array}$


In general, the rather small net effects resulted from stronger (gross) stabilizing effects being diminished by even larger destabilizing effects in particular years. France again is an exception, as the stabilizing effects were very large and were relatively little diminished by years when the effects were destabilizing. Figure 1 makes clear how little public enterprise investment influenced economic developments in Belgium, Sweden, and the United States, and how substantially they altered the course of events in France and Italy; the destabilizing nature of the effects in the United Kingdom is also evident.

This first criterion for evaluating the net stabilizing effects is most relevant in those countries in which (a) public enterprise investments are strongly influenced by government policy, and (b) this policy is part of the general conjunctural economic policies. Understandably, our six countries vary considerably in these respects. The central government of France maintains the greatest degree of control, which perhaps helps to explain why public enterprise investment was a stronger stabilizing factor there than in any other country. Belgium and the United Kingdom also maintain rather close control, but they allow a greater degree of autonomy in the investment decisions of public enterprises than does France. In Italy, where the public enterprise sector has grown rapidly in importance, the central government has relatively little direct control, except in the case of some public utilities companies, because self-financing provides about 90 per cent of the investment funds. In Sweden, the central government controls rather closely the investment of public enterprises which belong directly to it, but these are few in number and importance; most of the enterprises belong to local government, and the influence over investment decisions is only indirect, through general credit market policies. The same is true of the United States, but the enterprises belonging directly to the central government are so few and small in importance that no separate data about their investments are published. We do know, however, that aside from the stockpiling of strategic materials by the central government, nearly all U.S. public enterprise investment is made by companies responsible to state and local authorities. Because of these substantial differences among the countries studied, it is not at all clear that the basis for appraising the stabilizing effects should be the impact on potential fluctuations in the GNP growth rate, given all other budget effects and exogenous influences.

A second possible comparison gives different results for some countries. We can ask whether in the absence of any budget changes the net effect of changes in public enterprise investment alone has been generally stabilizing or destabilizing. In order to answer this it is necessary to construct a series for GNP growth as it might have developed without any budget impact, by subtracting from actual GNP growth the total effect of all budget changes (public enterprise investment as well as general government). This hypothetical series is called the "pure cycle", because it attempts to estimate what GNP growth 
would have been if there had been no change in any government expenditures or revenues from one year to the next. The pure cycle still incorporates the effects of other government policies (e.g., monetary and direct controls) as well as of autonomous forces (e.g., private investment and exports) and endogenous mechanisms (e.g., leakages through private saving and imports). Hence the pure cycle is not so "pure", but it nevertheless is a useful analytical tool. Additional graphs illustrating the pure cycle and the relationships similar to those included in Figure 1 are not presented here, because the lines intersect to such a degree that interpreting them becomes more difficult than the help they might provide, but several interesting relationships to the pure cycle can be derived, and these accumulated effects are also included in Table 2.

Potential stabilization can be defined as the (absolute) difference between the pure cycle and the average GNP growth rate; potential stabilization for the period $1955-65$ is simply the accumulated sum of these annual differences. The effects are defined as stabilizing if they make GNP growth closer to the average than it would have been without them; otherwise they are destabilizing. The accumulated amount of potential stabilization (item 3 ) is roughly the same for four countries, Belgium, France, Italy, and Sweden; somewhat less for the United Kingdom; and considerably greater for the United States (it is well known that cyclical fluctuations, actual as well as potential, have been substantially larger in the U.S. than in the European countries).

Next the net stabilizing effects of public enterprise investment in relation to the pure cycle (item 2) can be calculated and then compared with the net effects already described (item 1). Although in every case the absolute amount of net stabilization differs according to which criteria are used, nevertheless for France, Italy, the United Kingdom, and the United States the general direction of the effects remains unchanged. That is to say, under both criteria for France and the United States the net effects were on balance stabilizing, while they were destabilizing for Italy and the United Kingdom. For Belgium, the few destabilizing effects which were calculated by the first method disappear when the impact of public enterprise investment is compared with the pure cycle, and for Sweden the net effects switch from somewhat destabilizing to somewhat stabilizing.

Item 4 shows the amount of potential stabilization achieved by the entire public sector; it is significant that a fair amount of stabilization was achieved in all countries except the United Kingdom, where the impact of all budget changes tended to be destabilizing on balance-a quantitative evaluation of the effects of the "stop/go" policies. Except for France and the United Kingdom, public enterprise investment played a minor role; most of the stabilizing effects must be attributed to the general government (item $4 \mathrm{~b}$ ).

There is a third criterion by which stabilization could be judged: in relation to potential output. The percentage of short-run stabilization 
achieved can differ substantially from what was accomplished in maintaining an economy's full economic potential. The United States is a good example, because while the amount of short-run stabilization was considerable, nevertheless during the period from 1955 to 1965 the economy continually functioned below its full potential. Hence by this criterion, the judgments of the stabilizing effects of public enterprise investment in the U.S. would have to be revised. As their absolute impact was so small (see Table 1), however, this is not an important consideration. All the European countries except Italy tended to run at nearly full or even over-full potential, so that judging the stabilizing impact of their public enterprise investment would not be greatly affected by this new criterion. For Italy, however, the economy's full potential was not reached until about 1962 or 1963 . Thus, it would have been possible for economic growth to have been higher than the actual average. This means that the destabilizing effects of public enterprise investment, which were due to a generally overexpansive character, would need to be revised downwards-at least up to 1962. It is worth noting, however, that the expansionary effects caused by public enterprise investment tended to increase throughout the period, although as the Italian economy approached closer to its full potential it would have been better if the expansionary impact had become increasingly smaller. After 1962 public enterprise investment had a definitely destabilizing impact in Italy.

\section{Summary and Conclusions}

It is possible to use several criteria to appraise the stabilizing or destabilizing impact of public enterprise investment. For some countries this makes it impossible to say conclusively whether the net effect was stabilizing or destabilizing, but we can at least attempt a reasonable evaluation for the six countries studied.

France is the only country for which by all three criteria the impact of public enterprise investment appears to have been definitely stabilizing. In the United States, the public enterprise sector is very small and its investment is almost entirely independent of government control. Nevertheless, changes in investment contributed to stability in the short run, but a greater overall expansionary impact would have been more desirable, since a higher level of demand would have helped the economy to function closer to its full potential. In Italy the short-run effects of public enterprise investment were definitely destabilizing, but this was due primarily to excessive expansion and viewed from the perspective of the economy's capacity to have grown more rapidly (at least up to 1962-63), the impact was probably a positive rather than a destabilizing factor. It seems clearer that, by all three criteria, the impact of changes in public enterprise investment after 1962 was destabilizing. For Belgium and Sweden, judgment must be reserved, because 
in both cases the effect of public enterprise investment was somewhat destabilizing if the impact of all other government budget changes is taken as given but stabilizing if it is compared with what might have occurred in the absence of all government budget changes. In both countries, however, public enterprise investment was relatively small and had little influence on the course of economic events.

In sum, the impact of public enterprise investment was destabilizing only in the case of the United Kingdom, while for the other five countries it was generally a stabilizing factor, albeit a small one except in France, where it had an important stabilizing influence.

\section{REFERENCES}

1. E. CaRy Brown: "Fiscal Policy in the Thirties: A Reappraisal", Am. Econ. Rev. 46 (December 1956), pp. 857-79.

2. Richard E. CAVES and Associates: Britain's Economic Prospects (Washington, D.C., The Brookings Institution, 1968).

3. Bent HANSEN assisted by Wayne W. SNyder: Fiscal Policy in Seven Countries, 1955-65 (Paris, Organization for Economic Co-operation and Development, 1969).

4. Bent HANSEN: "Statsbudgetens verkningar", Ekonomisk Tidskrift (1959:3).

5. Assar LINDBECK: "Stadsbudgetens verkningar pa konjunkturutveckligen", SOU 1956: 48, Stockholm.

6. Richard A. Musgrave: “On Measuring Fiscal Performance", Rev. Ec. Stat. 66 (May 1964), pp. 213-20. 